\title{
INCLUSÃO E DESENVOLVIMENTO A FACE OCULTA DA EXCLUSÃO ESCOLAR
}

\author{
José Afonso Baptista ${ }^{1}$
}

\begin{abstract}
Resumo: A exclusão escolar, que alimenta a exclusão social, assume ainda foros de verdadeira calamidade, quer a nivel mundial, quer a nivel nacional. Esta é a principal causa da marginalidade, do desemprego, da fome, da miséria, do roubo organizado e do crime violento. São milhões de cidadãos em grande parte improdutivos, que não pagam impostos e que sobrevivem ao abrigo dos sistemas sociais que todos pagamos. No nosso país, à excepção do ensino superior, o acesso à educação está assegurado, mas há ainda centenas de milhares de alunos que anualmente vêem interrompido o seu percurso, com enormes prejuízos financeiros e sociais que não aproveitam a ninguém.

Existem várias formas de exclusão escolar que afectam ainda uma parte importante da população mundial: crianças, jovens e adultos que ainda não têm acesso à escola, alunos que a escola exclui $e$ abandona precocemente, pessoas com necessidades educativas especiais, deficientes ou não, que a escola ainda não aprendeu a educar, e todas as crianças e jovens que são vítimas de um modelo de escola organizado para a exclusão sistemática de uma parte importante dos seus alunos.

Para responder a este estado de calamidade e evitar os prejuizos incalculáveis, gerou-se um movimento mundial no sentido de garantir a educação a todos os cidadãos, sem excepção, criando condições de acesso nos países em vias de desenvolvimento, e concebendo novos modelos de educação e de escola, nos países desenvolvidos, capazes de educar todos sem excluir ninguém e sem deixar nenhum aluno para trás.

Este movimento, rumo à inclusão, tem vindo a ser coordenado pela Organização das Nações Unidas e pelas suas Agências, com iniciativas e contribuições importantes de alguns países e com o compromisso assumido pela comunidade das nações.
\end{abstract}

\footnotetext{
${ }^{1}$ Universidade Católica Portuguesa. E-mail: jab2437@ gmail.com
} 
Palavras-chave: exclusão, inclusão, dimensões da exclusão, marcos históricos da educação inclusiva

\begin{abstract}
The exclusion from school, the origin of social exclusion, has the dimension of a true world calamity, also assuming unacceptable proportions at a national level. The consequences are unemployment, hunger, misery, organized robbery and violent crime. Millions of unproductive citizens are paying no taxes and surviving under the protection of social systems that we all pay. In our country, with the exception of the higher education, access to school is guaranteed but we still have hundreds of thousands of pupils interrupting their school progression, with huge financial losses and social problems that do not benefit anyone.

There are several ways throughout the world in which people can be excluded from school: children and adults are deprived of access to school, pupils are excluded early from school, people with special education needs (disabled or not) are excluded because the school has not learned to teach them, and all the students that are victims of a school model organized for the systematic exclusion of an important part of their pupils.

A world movement has emerged trying to respond to this calamity and prevent the uncalculated losses. This movement aims to guarantee the education of all citizens, without exception, generating conditions to access school in the undeveloped countries and conceiving new education and school models in the developed communities, able to educate all without exclusion and leaving no child behind.

This movement is being carried under the coordination of the United Nations Organization and their Agencies, with a significant contribution from some countries and the commitment of the community of nations.
\end{abstract}

Key words: exclusion, inclusion, dimensions of exclusion, historic landmarks for inclusion

\title{
1. Educação, a força motriz do mundo actual
}

No modelo de sociedade a que chegamos, a educação é a energia que organiza e faz mover o mundo, que ilumina o espírito para alcançar os desígnios do bem-estar, da harmonia e entendimento entre todos os homens. É uma evidência que um analfabeto não tem a força criadora de um cidadão com os mais elevados níveis de educação e formação, do mesmo modo que um povo com baixos níveis de instrução não pode competir com os países onde a escolaridade de longa duração foi estabelecida há cem ou duzentos anos. Intimamente ligada ao sucesso das pessoas e dos povos, a educação define fronteiras entre ricos e pobres e delimita a geografia entre países desenvolvidos e países em vias de desenvolvimento, pondo em contraste vastas regiões do globo, 
com coincidências significativas entre os níveis de literacia e os níveis de desenvolvimento humano.

Observando o mapa mundial da literacia, verificamos que os níveis mais elevados de educação se concentram sobretudo no norte da Europa e da América do Norte e, no hemisfério sul, na Austrália e na Argentina. A África, globalmente, aparece com os índices mais baixos, juntamente com algumas regiões da Ásia. Estas são as regiões afectadas pela exclusão de primeiro nível, a das crianças e jovens que ainda não têm escola e de muitos adultos excluídos por não saberem ler.

Figura 1: Mapa Mundial da Literacia das Nações Unidas para o Desenvolvimento (World literacy map UNHD_2007_2008.png).

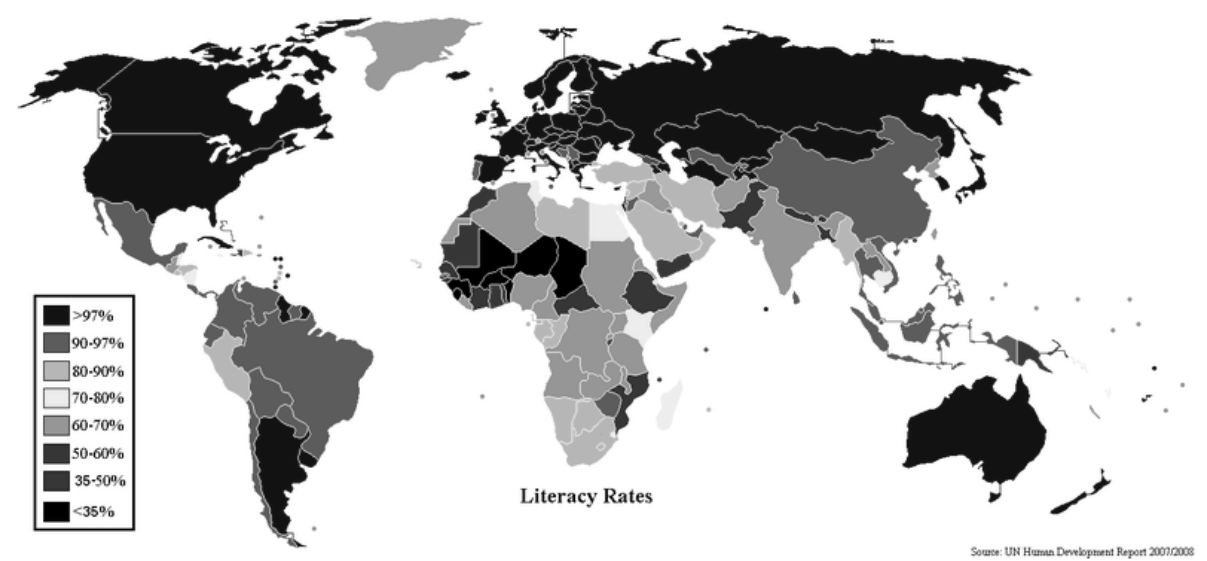

Fonte: Wikipédia.

No mapa das Nações Unidas para o Desenvolvimento Humano (2009), os países com os níveis mais elevados de desenvolvimento são os mesmos onde a literacia é mais elevada. Não é linear a correlação entre os níveis de literacia e o índice de desenvolvimento humano, mas a educação é um factor determinante e tornou-se a chave indispensável para a construção de um mundo melhor, mais próspero e mais seguro.

A sociedade actual está organizada de tal modo que não existe espaço para os analfabetos. Estão excluídos de tudo, dependentes de todos, não produzem riqueza, não pagam impostos, têm de ser sustentados pelo Estado, são um peso morto para a sociedade. Uma pessoa com elevados níveis de educação tem outra visão, outros recursos, outras competências de intervenção.

Se elevarmos esta análise à dimensão de um país, de um continente ou da humanidade, teremos outra visão da importância da educação para o incremento 
e elevação dos níveis de riqueza e de bem-estar, na luta contra a fome e a miséria, na superação das desigualdades, na compreensão das diferenças, na superação dos fundamentalismos políticos, ideológicos e religiosos, na conquista da paz, da justiça e da harmonia entre os homens. Retomando a metáfora inicial, o principal recurso no mundo actual está nas pessoas e a educação é a energia que as valoriza.

Figura 2: Índice de Desenvolvimento Humano (2009).

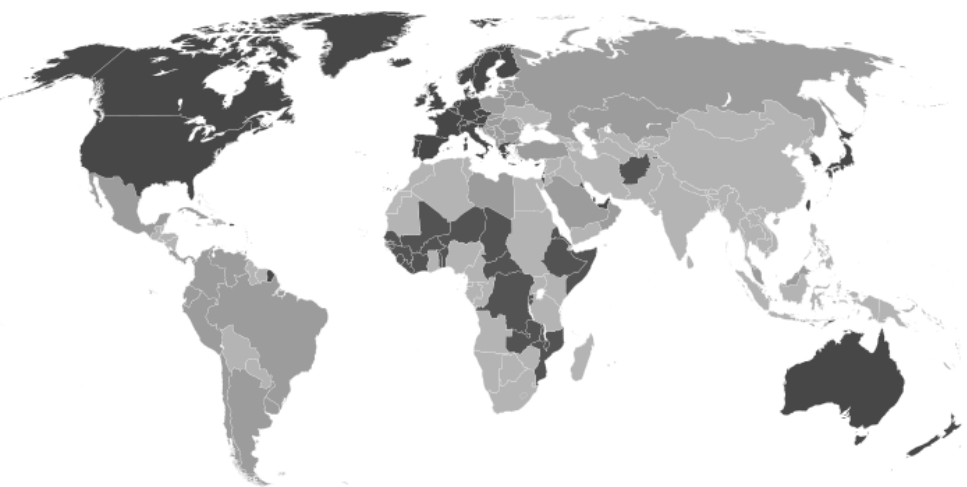

Fonte: Wikipédia.

Ao pôr em destaque esta evidência, pretende-se apenas chamar a atenção e realçar os graves prejuízos que resultam da existência de milhões e milhões de pessoas que passam à margem da escola e de outras tantas que a escola não soube ou não pôde ensinar de forma consistente e duradoura. Para muitos, a escola foi um episódio sem consequências. Uma parte importante da humanidade, sofrendo o estigma da exclusão, não contribui, como poderia, nem para uma sobrevivência autónoma e digna, nem para o progresso e bem-estar de todos.

A Organização das Nações Unidas, globalmente, mas também algumas das suas Agências, como a UNESCO, a UNICEF e o PNUD, assim como a OCDE e o Banco Mundial, têm desempenhado um papel fundamental na expansão da Educação e na luta contra a exclusão. O papel destas organizações dirige-se especialmente ao apoio aos países mais carenciados em matéria de Educação, mas tem sido também importante na transnacionalização das políticas educativas e no reforço de um sistema educativo mundial.

As desigualdades entre pessoas, povos, países e os contrastes chocantes entre vastas regiões do globo são a face visível do incumprimento dos direitos 
humanos, com reflexos evidentes na pobreza e na fome de que sofre ainda uma parte da humanidade.

\section{Exclusão escolar: uma calamidade mundial}

A partir da Declaração Universal dos Direitos Humanos (DUDH) (1948), e com particular acuidade na Conferência Mundial sobre Educação Para Todos (UNESCO, 1990), o princípio da universalidade constituiu-se como finalidade prioritária para a educação a nível mundial. É este princípio que põe em relevo a necessidade da mudança de paradigma, a necessidade de erradicar o paradigma da exclusão e abrir portas à inclusão. A nível mundial, os objectivos estão definidos, e bem definidos. Falta criar as condições concretas, em cada país, em cada escola, que permitam levar à prática esses objectivos. Que limites, que obstáculos, que difículdades se levantam para a realização deste desígnio?

A exclusão parece estar inscrita nos genes do ser humano. Excluímos os que não são da nossa raça, os que não pensam como nós, os que não são da nossa religião, do nosso partido político, da nossa condição social. Excluímos os diferentes, excluímos os deficientes. A própria escola, em muitos países, está envolvida numa teia de exclusão que não é fácil contrariar. A prática da selecção, da reprovação, da exclusão, está de tal modo enraizada na mente de professores, de pais, dos próprios alunos, que a inclusão, embora seja uma evidência que ninguém ousa contestar, encontra resistências em todos os actores. Defender a inclusão em Portugal ainda é remar contra a maré. O próprio Ministério da Educação, que legisla a inclusão, impõe um regime de avaliação dos alunos e um sistema de exames inspirados no paradigma da exclusão.

São múltiplas as modalidades da exclusão fabricadas pela escola. João Barroso (2003, p.27) destaca quatro:

- "A escola exclui porque não deixa entrar os que estão fora;

- A escola exclui porque põe fora os que estão dentro;

- A escola exclui "incluindo";

- A escola exclui porque a inclusão deixou de fazer sentido".

Esta categorização explica de forma clara, não só a exclusão histórica, do passado, mas a realidade presente, actual, em que tanto os governantes como os profissionais da educação disfarçam, muitas vezes, a exclusão mais absurda sob o eufemismo perverso da "inclusão" (Baptista, 2008).

\section{As quatro grandes dimensões da exclusão escolar}

Tomando como base e complementando a categorização proposta por João Barroso, analisaremos quatro dimensões da exclusão escolar actual:

1. O acesso à escola ainda é negado a muitos milhões de crianças; 
2. Muitos milhões de alunos ainda abandonam ou são excluídos precocemente da escola;

3. A escola ainda não aprendeu a educar os alunos diferentes, deficientes ou com dificuldades de aprendizagem;

4. O paradigma da exclusão continua a ser imposto por muitos sistemas educativos e por muitas escolas, mesmo quando afirmam o princípio da inclusão.

\section{O acesso à escola ainda é negado a muitos milhões de alunos}

Não obstante o compromisso assumido em 1948 pela comunidade das nações (DUDH), a realidade revelada 42 anos depois, na Conferência Mundial sobre Educação Para Todos (1990), deixa bem claro o número de pessoas ainda privadas do direito à educação: "mais de 100 milhões de crianças, das quais pelo menos 60 milhões são meninas, não têm acesso ao ensino primário; mais de 960 milhões de adultos - dois terços dos quais mulheres - são analfabetos, e o analfabetismo funcional é um problema significativo em todos os países industrializados ou em desenvolvimento; mais de um terço dos adultos do mundo não têm acesso ao conhecimento impresso, às novas habilidades e tecnologias, que poderiam melhorar a qualidade de vida e ajudá-los a perceber e a adaptar-se às mudanças sociais e culturais; e mais de 100 milhões de crianças e incontáveis adultos não conseguem concluir o ciclo básico, e outros milhões, apesar de concluí-lo, não conseguem adquirir conhecimentos e habilidades essenciais". Os números falam por si, pondo a nu a calamidade mundial que impede uma parte importante da humanidade de se integrar na sociedade do conhecimento e da informação.

O objectivo estabelecido nesta Conferência Mundial e o apelo feito aos participantes foi o de mobilizar esforços para implementar o "acesso universal e conclusão da educação fundamental até o ano 2000". Contudo, passados 20 anos, a UNESCO (2010) salienta que o número de crianças fora da escola sofreu uma redução de 33 milhões mas prevê ainda dificuldades em atingir em 2015 os objectivos definidos em 1990 para 2000, lembrando que em 2010 existem ainda 72 milhões de crianças fora da escola. A crise económica mundial não favorece a recuperação, prevendo-se que 56 milhões de crianças em idade escolar permanecerão fora da escola em 2015, se as tendências actuais se confirmarem.

A geografia da exclusão é fácil de delimitar. Basta olhar para os mapas da literacia e do desenvolvimento humano, que a situam nos países em vias de desenvolvimento. Para termos uma visão mais clara das taxas de escolarização e das diferenças regionais, atente-se no quadro seguinte: 
Quadro 1: Cálculo das taxas líquidas de escolarização por grupos de idade e por região

\begin{tabular}{|c|c|c|c|c|c|c|}
\hline $\begin{array}{l}\text { Região / Grupo de } \\
\text { idade }\end{array}$ & \multicolumn{2}{|c|}{$\begin{array}{l}\text { 6-11 anos } \\
\text { M }\end{array}$} & \multicolumn{2}{|c|}{ 12-17 anos } & $\begin{array}{l}18-2 \\
M\end{array}$ & $\mathrm{~F}$ \\
\hline África subsaariana & 55,2 & 47,4 & 46,0 & 35,3 & 9,7 & 4,9 \\
\hline Estados árabes & 83,9 & 71,6 & 59,2 & 47,1 & 24,5 & 16,3 \\
\hline $\begin{array}{l}\text { América latina/ } \\
\text { Caraíbas }\end{array}$ & 88,5 & 87,5 & 68,4 & 67,4 & 26,1 & 26,3 \\
\hline $\begin{array}{l}\text { Ásia de } \\
\text { Leste/Oceânia }\end{array}$ & 88,6 & 85,5 & 54,7 & 51,4 & 19,5 & 13,6 \\
\hline Ásia do Sul & 84,3 & 65,6 & 50,5 & 32,2 & 12,4 & 6,6 \\
\hline $\begin{array}{l}\text { Países } \\
\text { desenvolvidos }\end{array}$ & 92,3 & 91,7 & 87,1 & 88,5 & 40,8 & 42,7 \\
\hline
\end{tabular}

Fonte: UNESCO: BIE, 1996.

As consequências desta situação traduzem-se em migrações em massa, conduzindo à invasão dos países ricos pelos excluídos dos países pobres. A crise económica global torna mais lento o processo de escolarização dos marginalizados, como já vimos. Mas é previsível que a recente emancipação dos povos de África, alguns com um crescimento económico surpreendente, e o fim da guerra, possam atenuar os efeitos desta crise.

\section{Muitos milhões de alunos ainda são precocemente excluídos da escola}

Como se não bastasse o número de crianças e adultos que não têm acesso à escola, um grande número de escolas em muitos países do mundo retêm, excluem e levam muitos alunos ao abandono escolar antes de concluírem a escolaridade obrigatória. Em alguns países, as taxas de retenção são muito elevadas. Num Relatório sobre o problema da retenção (UNESCO, 1995), podemos ver que a percentagem de repetentes no ensino primário ultrapassa os $20 \%$ em 22 países e, em seis deles, reprovam mais de metade dos alunos. Se pensarmos, acrescenta o mesmo Relatório, que uma boa parte dos repetentes não chegarão ao fim da escolaridade, veremos melhor a dimensão do problema.

Retomando o mesmo tema um ano depois, a UNESCO (1996, p.5) afirma: "levando em conta a considerável dimensão do fenómeno, a sua concentração 
nos primeiros anos do ensino primário e nas escolas frequentadas por alunos oriundos de meios pobres, a sua influência devastadora no domínio social e psicológico sobre os repetentes e as suas famílias e ainda as suas pesadas consequências financeiras, deve ser considerado um problema muito grave que os sistemas educativos não só têm de aliviar mas também de resolver".

1. As taxas de retenção são diferentes de país para país. "Na Europa do Sul (Id., ib) e nos países em desenvolvimento influenciados por esta região (países francófonos, lusófonos e hispanófilos) a retenção é prática corrente, enquanto nos países da Europa do Norte e nos países em desenvolvimento influenciados pela sua tradição optaram pela passagem automática ao ano seguinte. Não está provado que os países do primeiro grupo tenham melhores resultados (...) que os do segundo grupo"2. Bem pelo contrário, podemos acrescentar hoje.

Em Portugal, as taxas de retenção têm diminuído nos últimos anos, nem sempre porque os alunos aprendam mais e melhor. Mas basta entrarmos em qualquer escola do ensino básico ou do ensino secundário para verificarmos que a retenção é ainda uma prática corrente, faz parte da cultura e da organização da escola. Em sucessivos inquéritos e levantamentos realizados, nas respectivas escolas, por professores que frequentam mestrados e cursos de pós-graduação em ciências da educação na Universidade Católica Portuguesa, alguns já em 2010, verifica-se que a retenção continua a ser a estratégia, quanto a nós errada, para resolver os problemas de aprendizagem dos alunos.

O que mais preocupa é a dimensão do problema. Num estudo realizado por Joaquim Azevedo (2003) sobre o rendimento escolar nas escolas secundárias e nas escolas profissionais e em que se analisa a capacidade das escolas para diplomarem os seus alunos nos três anos de duração do curso, verifica-se que, nos cursos gerais, apenas $47 \%$ dos alunos consegue diplomar-se no período previsto; nos cursos tecnológicos, essa percentagem fica nos $30 \%$, sendo um pouco melhor nos cursos profissionais: $64 \%$, num universo significativamente mais reduzido (ver quadros das pp. 23-24).

A dimensão actual do problema da retenção entre nós é analisada por Olímpia Teixeira (2010), que põe em relevo o seu custo económico e social. Citando a exministra da educação, Maria de Lurdes Rodrigues, relativamente aos resultados de 2006/2007, transcreve (p.5): "Feitas as contas, os 148.634 estudantes do $2 .^{\circ}$ ao $12 .^{\circ}$ anos que ficaram retidos ou abandonaram a escola custaram mais de 743 milhões de euros aos bolsos dos portugueses, sem quaisquer resultados". E acentua, citando ainda a ex-ministra, que "o custo [dos chumbos] é sempre insignificante em relação ao custo social de ter pessoas sem qualificação no

\footnotetext{
${ }^{2}$ Tradução do autor.
} 
mundo do trabalho". Para a ex-ministra, "o chumbo de alunos é um mecanismo retrógrado e antigo. Facilitismo é chumbar, rigor e exigência é trabalhar".

Focalizando mais especificamente o ensino secundário, Olímpia Teixeira (2010, p.4) apresenta este cenário: "De acordo com dados estatísticos do GEPE (2007), concluíram o $12^{\circ}$ ano dos cursos científico-humanísticos, em 2006/2007, 43.132 alunos. Eis um valor que nos assusta, se tomarmos como referência o número de matriculados, na oferta formativa mencionada, no $10^{\circ}$ ano, em 2004/05, o ano lectivo em que o ciclo de estudos se iniciou: 205671 alunos. A relação percentual é de 20,97\%". E acrescenta mais adiante (p.5): "Considerando, de forma mais particular, os valores de retenção para o ensino público e privado, ficamos a saber que, em 2007/08, a taxa de retenção e desistência no $12^{\circ}$.ano, no continente, foi de 32,3 ".

Concluindo com as palavras de João Barroso (2003, p.27), a "escola exclui porque não deixa entrar os que estão fora e exclui ainda porque põe fora os que estão dentro".

\section{A escola ainda não aprendeu a educar os alunos deficientes, com dificuldades de aprendizagem ou simplesmente diferentes}

As crianças e jovens deficientes foram excluídos da educação e da escola ao longo dos séculos. Nos últimos 200 anos, ao mesmo tempo que se organizavam e estruturavam os sistemas educativos, foram surgindo instituições e redes sociais de acolhimento, procurando evitar que as crianças e jovens "deficientes" perturbassem a educação das crianças "normais" (Baptista, 2008; Sánchez, 2003). Como refere a Proposta de Lei do Ministro João Camoesas (1923), ao propor a criação de "escolas para anormais", "a existência de anormais nas escolas comuns, como sucede entre nós, constitui um obstáculo ao progresso dos alunos sãos e um verdadeiro perigo moral para eles. (...). Educados à parte (...) consegue-se torná-los capazes de um rendimento social que liberte a colectividade do seu peso morto de seres improdutivos" 3 .

Passado o período da exclusão pura e simples, em várias modalidades, e superada a fase da segregação e da institucionalização, que deixaram marcas profundas, idênticas à do racismo étnico e social, tão difíceis de erradicar, sabemos hoje que o peso morto não está nos deficientes, mas no grupo mais alargado das pessoas que a escola não tem sabido educar, na sua maioria sem deficiência visível. Uma grande parte das pessoas consideradas deficientes não tem a menor limitação cognitiva, podendo atingir os mais elevados níveis de educação e formação e podendo assumir as mais elevadas responsabilidades sociais e profissionais.

${ }^{3}$ Diário do Governo, II Série, p. 2258 ss, 2 de Julho de 1923. 
Actualmente estas crianças e jovens com deficiências já apresentam elevadas taxas de escolarização, até porque também estão abrangidas pela escolaridade obrigatória. O problema está em que as escolas e os professores ainda não estão suficientemente preparados para garantir o sucesso educativo destes alunos, sobretudo nas escolas regulares, que acolhem a grande maioria. Para termos uma ideia do número de crianças deficientes com necessidades educativas especiais, apenas em Portugal, veja-se o quadro seguinte:

Quadro 2: NEE/Portugal/2008

\begin{tabular}{|l|r|}
\hline Total alunos na Escolaridade Obrigatória incluindo NEE & 1235464 \\
\hline Total de alunos com NEE & 44747 \\
\hline Total de alunos NEE em escolas especiais segregadas & 3576 \\
\hline Total de alunos com NEE em salas segregadas das escolas regulares & 1336 \\
\hline Total de alunos com NEE em escolas inclusivas & 39835 \\
\hline
\end{tabular}

Fonte: Special Needs Education. Country Data (2008). European Agency for Development in Special Needs Education. www.european-agency.org . Inclui dados dos países da UE.

Mas não é apenas a população escolar com deficiências e incapacidades que levanta dificuldades aos professores e profissionais da escola regular. A este grupo foi-se juntando o dos alunos com dificuldades de aprendizagem, eventualmente com menores aptidões cognitivas, mas também o de alunos desprotegidos, desfavorecidos, oriundos de ambientes familiares e sociais desestruturados, das famílias do rendimento social mínimo, das famílias dos países de língua oficial portuguesa, as crianças de etnia cigana, crianças com perturbações psicológicas e afectivas e, ainda, alunos de outros grupos étnicos e linguísticos minoritários.

A própria referenciação e elegibilidade para a educação especial continuam a gerar dificuldades e controvérsias. O debate em torno do DL 3/2008, de 7 de Janeiro, e sobre a utilização da $\mathrm{CIF}^{4}$ como instrumento de referenciação e elegibilidade, são bem a prova desta dificuldade. Haverá alunos com reais problemas de aprendizagem que poderão ficar fora dos critérios de elegibilidade, enquanto outros poderão integrar o contingente da educação especial por fragilidades do foro social ou étnico. De resto, o que importa salientar aqui é o elevado número de crianças e jovens excluídos por serem deficientes ou diferentes, sem verem reconhecido o direito à educação ou sem que esse direito tenha sido levado à prática. A história da Educação Especial é feita de exclusão,

${ }^{4}$ Classificação Internacional de Funcionalidade, CIF, da Organização Mundial de Saúde (2001). 
de segregação, de institucionalização de pessoas, tantas vezes com aptidões para serem autónomas, independentes e plenamente envolvidas no mundo do trabalho e na participação social.

As razões desta rejeição residem muitas vezes na intolerância e na incapacidade de conviver com a diferença. A privação dos direitos democráticos e cívicos de milhões de cidadãos, injustamente considerados inaptos para a qualificação profissional, e consequentemente para o trabalho, chegou até aos nossos dias, sacrificando tantas pessoas inteligentes e aptas, sujeitando-as ao vexame da exclusão, da institucionalização, da assistência e da caridade, apenas por serem diferentes.

Como veremos adiante, o reconhecimento dos direitos das pessoas diferentes e deficientes, nos planos político e jurídico, está hoje consagrado nas convenções das organizações internacionais e nas leis da grande maioria dos países mas, mais uma vez, faltam em grande parte os recursos humanos qualificados e os meios financeiros e materiais para a formação de pessoas diferentes. É a parte do caminho que falta percorrer. Não basta ser livre, é preciso ter condições para o exercício da liberdade. Uma escola não se torna inclusiva pelo simples facto de receber todos os alunos que a procuram. É necessário também que tenha as respostas qualificadas e especializadas que esses alunos precisam. Se não tiver, a exclusão pode ser ainda mais cruel.

\section{A escola em Portugal ainda está organizada para a exclusão}

É preciso que fique bem claro: a escola exclui porque foi e está organizada para excluir, independentemente das características e dificuldades dos alunos. A prova está em que há países que adoptaram o modelo da inclusão, - os países nórdicos, como vimos -, onde a escola não rejeita os alunos, nem pratica a retenção, nem exclui ninguém. Porque é que a escola em Portugal, e noutros países, segue o paradigma da exclusão?

A escola de massas nasce no fim do século XVIII e início do XIX (Soysal, 1989). A necessidade de instituir o ensino colectivo obrigou a distribuir os alunos por grandes grupos, as classes ou turmas. Classificar é distribuir por classes (Barroso, 1995). Quando o critério da classificação é o nível de conhecimentos, os alunos são excluídos à entrada ou à saída de um ciclo de formação se não estiverem ou se não tiverem atingido o nível pré-definido pela escola, de modo a assegurar a homogeneidade das classes. Nasce assim o paradigma da exclusão, adoptado em Portugal e noutros países do sul da Europa.

Os países nórdicos não seguiram este paradigma, adoptando o critério da idade em vez do nível de conhecimentos e seguindo a progressão automática. A prevenção do insucesso assenta em duas medidas fundamentais: identificação, acompanhamento e apoio efectivo aos alunos que revelam dificuldades de aprendizagem ao longo da escolaridade obrigatória; orientação escolar e 
profissional, encaminhando os alunos para o ensino secundário de acordo com o seu perfil. Este é o grande desafio que temos pela frente, que não deve ser imposto por decreto, de um dia para o outro, sem preparação dos professores e sem a mentalização de pais e alunos.

Na concepção de um modelo de escola para o século XXI, a escola inclusiva, importa definir claramente como objectivos:

- Promover a transição do paradigma da exclusão para o da inclusão, que não rejeita nem exclui ninguém;

- Conceber a escola inclusiva como a escola de todos, pensada para todos, e não como a escola dos "herdeiros" (Bourdieu \& Passeron, 1964), que tolera a presença dos excluídos, sem a menor atenção às diferenças.

Reside aqui a mudança essencial na escola, da fase da integração para a da inclusão. Na primeira, é o aluno que tem de se adaptar ao perfil exigido pela escola; na segunda, é a escola que tem de se organizar de acordo com o perfil dos alunos.

\section{Marcos históricos fundamentais rumo à inclusão}

As políticas de exclusão e de selecção, porventura inevitáveis antes de Gutenberg e das sucessivas revoluções industriais, são inaceitáveis em democracia e nas economias baseadas no conhecimento e na informação. A humanidade não pode suportar o prejuízo de tão elevado número de analfabetos, quer no plano financeiro quer no plano social. Daí resultam os esforços da Organização das Nações Unidas na liderança das iniciativas e das políticas de concertação rumo à inclusão que têm o seu impulso inicial em 1948, com a Declaração Universal dos Direitos Humanos, que proclama o direito de todos à educação e define o princípio da universalidade, implicando todos os países no cumprimento deste direito. Este é o primeiro marco histórico nas políticas de inclusão, tanto mais importante quanto é certo que envolve o compromisso da sociedade das nações.

Ao alargar este direito às pessoas com deficiências ou incapacidades, foi igualmente importante a sua escolarização obrigatória e a sua integração na escola regular. Em 1975, os Estados Unidos promulgam a Public Law 94-142, Education of All Handicapped Children Act (EAHCA), que se mantém ainda hoje, depois de revista e actualizada, agora com a designação Individuals with Disabilities Education Act (IDEA), pondo em destaque o acrónimo que daí resulta. Este é o segundo marco histórico rumo à inclusão, ao decretar a integração de TODAS as crianças deficientes ou incapacitadas.

Quase em simultâneo surge no Reino Unido o terceiro marco histórico rumo à inclusão, The Warnock Report, Special educational needs. Report of the Committee of Enquiry into the education of handicapped children and young 
people. O Relatório Warnock foi publicado em 1978 e a sua aplicação em lei verificou-se na reforma educativa de 1981.

A enorme importância destes dois marcos históricos está antes de mais na mudança de políticas em relação à educação das pessoas deficientes, mas está também na mudança de paradigma em educação especial, com um enorme impacto nos sistemas educativos e na organização das escolas em todo o mundo. É a rotura com os paradigmas da exclusão, da segregação e da institucionalização, e o início da integração que, em termos cronológicos, se mantém até à década de 90 . As crianças e jovens com necessidades educativas especiais vêem reconhecido o direito de serem educadas juntamente com os seus pares.

Na década de 90 dá-se o último passo rumo à inclusão, reiterando e consagrando agora, não apenas o princípio de universalidade da educação preconizado pela DUDH (1948), mas gerando o movimento da inclusão enquanto movimento de reorganização da escola. Trata-se da Conferência Mundial sobre Educação Para Todos (UNESCO, 1990) e da Conferência Mundial sobre Necessidades Educativas Especiais (UNESCO, 1994), o quarto e quinto marcos fundamentais da educação inclusiva.

O eixo cronológico da transição da fase da integração para a fase da inclusão é fácil de entender, mas é mais difícil entender o que faz a diferença na escola inclusiva. A escola inclusiva está centrada nas pessoas e nas aprendizagens. Recusando uma pedagogia padronizada em torno de programas uniformes e indiferentes às características de cada um, orientada pelos rituais burocráticos para decidir quem passa e quem chumba, a educação inclusiva centra as aprendizagens nas características e necessidades de cada pessoa. Todos são educáveis, todos podem aprender desde que as aprendizagens sejam organizadas à medida de cada um.

A escola inclusiva não reprova, não exclui, não deixa nenhum aluno para trás. Em termos práticos, nos países do sul da Europa, incluindo Portugal, decorre ainda o período da integração. Acolhendo todos, a escola ainda não aprendeu a educar todos, excluindo e deixando uma grande parte para trás. No norte da Europa, a inclusão faz o seu percurso sem exclusão, sem desperdícios, conseguindo dar a todos, de facto, uma escolaridade de longa duração bem sucedida.

\section{Conclusão}

A educação de todos, a educação inclusiva, que não exclui, é hoje uma exigência, sem alternativas, do modelo de sociedade em que vivemos, que não tem espaço para os iletrados. Está em causa o desenvolvimento e sobrevivência de milhões de pessoas, a economia e bem-estar de todos, a harmonia entre povos e cidadãos, a própria salvaguarda do planeta. 
O século XX afirmou-se como o século da escola, da escolaridade obrigatória, da aprendizagem ao longo da vida. Esse objectivo foi em grande parte atingido em muitos países desenvolvidos e representou um avanço enorme nos últimos 40 anos, com reflexos evidentes nos níveis de bem-estar da humanidade. De acordo com o IDH $2010^{5}$, a esperança de vida aumentou de 59 para 70 anos, a taxa de escolarização de alunos do ensino básico e secundário passou de 55 para 70 por cento entre 1970 e 2010, ao mesmo tempo que o produto interno bruto (PIB) duplicou e passou a média dos dez mil dólares.

Este é o resultado do movimento irreversível iniciado em 1948. Em Portugal, o caminho está a meio. Temos escola para todos, mas falta ainda que a escola aprenda a educar todos. Esse é o caminho para o desenvolvimento. ${ }^{6}$

5 Human Development Report 2010. 20th Anniversary Edition http://hdr.undp.org/en/media/HDR_2010_EN_Complete.pdf

${ }^{6}$ Para uma abordagem mais alargada deste artigo, veja-se Baptista, 2011 


\section{Bibliografia}

ALVES, J. M. (2008). Os Exames do Ensino Secundário como dispositivos de regulação das aspirações - A ficção meritocrática, a organização da hipocrisia, e as acções insensatas. Porto: UCP.

AZEVEDO, J. (2003). Rendimento escolar nas escolas secundárias e nas escolas profissionais: resultados de uma amostragem. In Revista Portuguesa de Investigação Educacional. Lisboa: Universidade Católica Portuguesa, 2/2003. Disponível em: http://www.fmleao.pt

AZEVEDO, J. (Ed.). (2002). Avaliação das Escolas. Consensos e Divergências. Porto: Edições ASA.

AZEVEDO, J. (2007). Sistema educativo mundial. Ensaio sobre a regulação transnacional da educação. Vila Nova de Gaia: Fundação Manuel Leão.

BAPTISTA, J. A. (2008). Os surdos na escola. A exclusão pela inclusão. Vila Nova de Gaia: Fundação Manuel Leão.

BAPTISTA, J. A. (2011). Introdução às Ciências da Educação. Temas e Problemas da Educação Inclusiva. Lisboa: Universidade Católica Editora, PRO_LGP9.

BARREIRA, C \& Pinto, J. (2005). A investigação em Portugal sobre a avaliação das aprendizagens dos alunos (1990-2005). Investigar em Educação, 4, Sociedade Portuguesa de Ciências da Educação. Disponível em: http://www.educ.fc.ul.pt/docentes/msantos/spce.pdf

BARRoso, J. (1995). Os Liceus. Organização Pedagógica e Administração (1836-1960). Lisboa: FCG/JNICT.

BEANE, J. (2003). Integração curricular: a essência de uma escola democrática, Currículo sem Fronteiras, v.3, n.2, pp. 91-110, Jul/Dez. Disponível em:http://www.curriculosemfronteiras.org/vol3iss2articles/beane.pdf

BOURDIEU, P. \& Passeron, J.-C. (1964). Les héritiers. Paris: Les Éditions de Minuit.

BOURDIEU, P. \& Passeron, J-C (1970). La Reproduction. Éléments pour une théorie du système d'enseignement, Minuit.

CARNEIRO, R. (2001). "Aprender 2020", Fundamentos da Educação e da Aprendizagem. Vila Nova de Gaia: Fundação Manuel Leão.

CORREIA, L. M. (2003). Educação Especial e Inclusão. Porto: Porto Editora.

COSTA, J. A. (2007). Os projectos na escola: uma leitura crítica através da metáfora da hipocrisia organizada. In Projectos em educação contributos de análise organizacional (pp. 97-118). Aveiro: Universidade de Aveiro

DELORS, J. (1997). Educação, um tesouro a descobrir. Relatório para a UNESCO da Comissão Internacional sobre Educação para o século XXI. São Paulo: Cortez Editora. Disponível em: 
http://ns1.dhnet.org.br/dados/relatorios/a pdf/r_unesco educ tesouro des cobrir.pdf

Educação Inclusiva e Práticas de Sala de Aula nos $2^{\circ}$ e $3^{\circ}$ Ciclos do Ensino Básico (2005). Relatório Síntese da Agência Europeia para o Desenvolvimento da Educação Especial. Disponível em: http://www.europeanagency.org/publications/ereports/inclusiveeducation-and-classroom-practice-in-secondaryeducation/iecp_secondary_pt.pdf

EURYDICE (1995). A luta contra o insucesso escolar: um desafio para a construção europeia. Lisboa: DEPGEF/PEPT.

FERNANDES, D. (2005). Avaliação das aprendizagens: desafios às teorias, práticas e políticas. Lisboa: Texto Editores.

FERNANDES, D. (2006). Para uma teoria da avaliação formativa, Revista Portuguesa de Educação, 19(2), 21-50. Universidade do Minho: CIED. Disponível em: http://www.scielo.oces.mctes.pt/pdf/rpe/v19n2/v19n2a03.pdf

FERNANDES, D. (2007). Vinte e cinco anos de avaliação das aprendizagens: uma síntese interpretativa de livros publicados em Portugal. In A. Estrela (Org.). Investigação em Educação. Teorias e Práticas (1960-2005) (pp. 261-305). Lisboa: Educa.

FERNANDES, M. (1998). A mudança de paradigma na avaliação educacional. Educação, Sociedade \& Culturas, 9, 7-32.

FERNANDES, M. (2000). Mudança e Inovação na Pós-Modernidade. Perspectivas curriculares. Porto Editora.

FIGARI, G. (2007). A avaliação: história e perspectivas de uma dispersão epistemológica. In A. Estrela (Org.). Investigação em Educação. Teorias e Práticas (1960-2005) (pp. 227-260). Lisboa: Educa.

FORMOSINHO, J. (1987). O currículo uniforme pronto a vestir de tamanho único. In O insucesso escolar em questão. Cadernos de Análise Social da Educação. Braga, Univ. Minho, 41-50.

MÉNDEZ, J. M. Á. (2001). Avaliar para conhecer, examinar para excluir. Porto: Edições ASA.

MEIRIEU, P. (2006). Treize pistes pour des pratiques d'excellence en Zones d'Éducation prioritaire. Disponível em: http://www.meirieu.com/MANIFESTESETPROPOSITIONS/ozp_zep.pdf

NÓVOA, A. (1995). Prefácio à obra de João Barroso. Os Liceus. Organização Pedagógica e Administração (1836-1960). Lisboa: FCG/JNICT.

NÓVOA, A., B., João \& Ó, Jorge (2003): O Todo Poderoso Império do Meio. In Liceus de Portugal. Porto: Edições ASA.

NÓVOA, A. (n.d.). O lugar dos professores: terceiro excluído? Associação Portuguesa de Matemática. Disponível em: http://www.dgidc.minedu.pt/revista/revista8/pdf/lugar_professores.pdf 
PACHECO, J. A. \& Pereira, N. (2007). Estudos Curriculares: das teorias aos projectos de escola. Disponível em: http://www.scielo.br/pdf/edur/n45/a11n45.pdf

PERRENOUD, P. (2003). Dez princípios para tornar o sistema educativo mais eficaz. In J. Azevedo (Coord.). Avaliação dos resultados escolares. Porto: Edições ASA.

RODRIGUES, D. (2003). Educação e Diferença. Valores e Práticas para uma Educação Inclusiva. Porto: Porto Editora.

ROLDÃO, M. ${ }^{a}$ Céu \& et al. (2000). Currículo: gestão diferenciada e aprendizagens de qualidade. Lisboa: AEEP.

SÁNCHEZ, P. (2003). Educación Inclusiva: Una Escuela para Todos. Málaga: Ediciones Aljibe.

SANTOS, A. \& et al. (2009). Escolas de Futuro. 130 Boas práticas de Escolas Portuguesas. Porto: Porto Editora.

SANTOS GUERRA, M. (1998). Evaluar es comprender. Buenos Aires: Edit. Magistério del Rio de la Plata.

SANTOS GUERRA, M. (2001). A Escola que Aprende. Porto: Edições ASA.

SANTOS GUERRA, M. (2002). Entre Bastidores. O lado oculto da organização escolar. Porto: Edições ASA

SANTOS GUERRA, M. (2002). Como num Espelho - Avaliação qualitativa das escolas (Conferência proferida no Curso de Verão de 2001). In J. Azevedo (Org). Avaliação das Escolas - Consensos e Divergências (pp. 11 a 31). Porto: Edições ASA.

SMITH, M. K. (1996, 2000). Curriculum theory and practice' the encyclopaedia of informal education. Disponível em: www.infed.org/biblio/b-curric.htm.

SOYSAL, Y. N. \& Strang, D. (1989). A construção dos primeiros sistemas de educação de massas no século dezanove na Europa. Sociology of Education, Vol. 62, No. 4 (Oct.), 277-288.

Special Needs Education. Country Data (2008). European Agency for Development in Special Needs Education. Disponível em: www.europeanagency.org

TEIXEIRA, O. (2010). A Retenção no Ensino Secundário: A Falácia Racional e o Facilitismo. Lisboa: Universidade Católica Portuguesa.

TEIXEIRA, O. (2010). A Retenção no Ensino Secundário. Lisboa: Universidade Católica Portuguesa.

UNDP, Human Development Report 2010. 20th Anniversary Edition. Disponível em: http://hdr.undp.org/en/media/HDR_2010_EN_Complete.pdf

UNDP World Literacy Map United Nations Human Development. Mapa da Literacia Mundial do Programa das Nações Unidas para o Desenvolvimento. Disponível em: http://pt.wikipedia.org/wiki/Programa das Na\%C3\%A7\%C3\%B5es Uni das_para_o_Desenvolvimento 
UNESCO (1990). Declaração Mundial Sobre Educação Para Todos. Plano de Acção Para Satisfazer as Necessidades Básicas de Aprendizagem. Aprovada pela Conferência Mundial sobre Educação para Todos, Jomtien, Tailândia - 5 a 9 de Março de 1990. Disponível em: http://www.pitangui.uepg.br/nep/documentos/Declaracao\%20\%20jomtien\%20-\%20tailandia.pdf

UNESCO (1994). Declaração de Salamanca e Enquadramento da Acção na Área das Necessidades Educativas Especiais, Conferência Mundial sobre Necessidades Educativas Especiais: Acesso e Qualidade. Salamanca, Espanha, 7 a 10 de Junho. Disponível em: http://unesdoc.unesco.org/images/0013/001393/139394por.pdf

UNESCO (1995). Réduire les redoublements: problèmes et stratégies. Disponível em: http://www.unesco.org/iiep/fre/newsletter/1998/aprf1198.htm

UNESCO/BIE (1996). Le redoublement scolaire dans l'enseignement primaire. Analyse mondiale. Disponível em: http://unesdoc.unesco.org/images/0014/001493/149393fo.pdf

UNESCO (2004). Ten questions on inclusive education. Disponível em: http://www.unesco.org/en/inclusive-education/10-questions-on-inclusivequality-education/

UNESCO (2004). Changing Teaching Practices using curriculum differentiation to respond to students' diversity. Disponível em: http://unesdoc.unesco.org/images/0013/001365/136583e.pdf

UNESCO (2006). Sob a direcção de Jérôme Bindé. Para onde vão os Valores? Almada: Instituto Piaget.

UNESCO (2008). Uma Educação Inclusiva de Qualidade. Disponível em: http://www.bengalalegal.com/unesco.php

UNESCO (2009). Education for All Global Monitoring Report - Overcoming Inequality: Why Governance Matters. Disponível em: http://www.unesco.org/en/efareport/reports/2009-governance/

UNESCO (2010). Relatório de Monitoramento Global de Educação para Todos 2010. Disponível em: http://www.unesco.org/pt/brasilia/singleview/news/2010 education for all global monitoring report is being 1 aunched_19_january_in_new_york/browse/8/back/20950/cHash/3c63a765 $56 /$.

Warnock Report - Publication by the Warnock Committee (1978). Special Educational Needs. Report of the Committee of Inquiry into the Education of Handicapped Children and Young People. Department for Education and Science. Londres: HMSO. Texto integral em Inglês. Disponível em: http://www.educationengland.org.uk/documents/warnock/ 